\title{
Apontamentos sobre o Desenvolvimento Humano Municipal no Estado de Mato Grosso do Sul
}

\author{
Notes on Municipal Human Development in the State of Mato Grosso do Sul \\ Notas sobre el desarrollo humano municipal en el estado de Mato Grosso do Sul
}

\author{
Adriano Renzi ${ }^{1}$ \\ Jandir Ferrera de Lima² \\ Carlos Alberto Piacenti²
}

Recebido em: 06/12/2019; revisado e aprovado em 07/05/2020; aceito em 17/07/2020

DOI: http://dx.doi.org/10.20435/inter.v22i2.2843

\begin{abstract}
Resumo: Esse artigo analisa a evolução do Índice FIRJAN de Desenvolvimento Municipal (IFDM) à luz da teoria da causação circular e acumulativa e da teoria do crescimento endógeno. O período selecionado para esta análise foi de 2005 a 2016, e tal análise realiza duas formas de comparação: a primeira comparou o índice IFDM dos municípios sul-mato-grossenses à média do próprio estado, e a segunda comparou os municípios à média do Brasil. Os resultados obtidos evidenciaram que a dinâmica de desenvolvimento econômico para os municípios de Mato Grosso do Sul, Brasil, foi significativamente superior à dinâmica nacional, mas ainda não foi suficiente para superar a situação de círculo vicioso da pobreza na qual se encontra uma parcela considerável de municípios em 2016.
\end{abstract}

Palavras-chave: Índice FIRJAN; desenvolvimento econômico; desenvolvimento regional; causação circular; desenvolvimento endógeno.

\begin{abstract}
This paper analyzes the evolution of the FIRJAN Index of Municipal Development (IFDM) based on the theory of circular and cumulative causation and the theory of endogenous growth. The period selected for this analysis was from 2005 to 2016 and this analysis performs two forms of comparison: the first one compared the IFDM index of the municipalities of Mato Grosso do Sul State, Brazil, to the average of the State itself, and the second compared the municipalities to the average of Brazil. The results obtained showed that the dynamics of economic development for the municipalities of Mato Grosso do Sul was significantly higher than the national dynamics, but it was still not enough to overcome the situation of a vicious circle of poverty in which a considerable number of municipalities are found in 2016.
\end{abstract}

Keywords: FIRJAN Index; economic development; regional development; circular causation; endogenous development.

Resumen: Este artículo analiza la evolución del Índice FIRJAN de Desarrollo Municipal (IFDM) a la luz de la teoría de la causalidad circular y acumulativa y de la teoría del crecimiento endógeno. El período seleccionado para este análisis fue de 2005 a 2016, y este análisis realiza dos formas de comparación: el primero comparó el índice IFDM de los municipios de Mato Grosso do Sul, Brasil, con el promedio del Estado, y el segundo comparó los municipios con el promedio de Brasil. Los resultados obtenidos mostraron que la dinámica del desarrollo económico para los municipios de Mato Grosso do Sul fue significativamente mayor que la dinámica nacional, pero aún no fue suficiente para superar la situación de un círculo vicioso de pobreza en el que se encuentra un número considerable de municipios en 2016.

Palabras clave: Índice FIRJAN; desarrollo económico; desarrollo regional; causalidad circular; desarrollo endógeno.

\section{INTRODUÇÃO}

A região Centro-Oeste do Brasil tem apresentado, nos últimos anos, uma evolução significativa em termos de desenvolvimento socioeconômico. Com base no Índice FIRJAN de Desenvolvimento Municipal (IFDM) (FIRJAN, 2014), tal região apresentou 86,4\% dos seus municípios, com índice acima de 0,6 ponto, ou seja, com 374 municípios apresentando nível de

\footnotetext{
${ }^{1}$ Universidade Federal da Grande Dourados (UFGD), Dourados, Mato Grosso do Sul, Brasil.

${ }^{2}$ Universidade Estadual do Oeste do Paraná (UNIOESTE), Toledo, Paraná, Brasil.
} 
desenvolvimento moderado e 25 apresentando alto nível de desenvolvimento. Esse desempenho positivo da região Centro-Oeste tem reduzido a sua distância em relação às regiões mais desenvolvidas do país (Sul e Sudeste). Essa região é composta pelos estados de Goiás, Mato Grosso e Mato Grosso do Sul e pelo Distrito Federal.

Todos os estados da região Centro-Oeste apresentam distribuição de resultados melhores em comparação com o nível de desenvolvimento nacional. Com mais detalhe, os estados de Goiás, Mato Grosso e Mato Grosso do Sul possuem, respectivamente, 89,3\%, 85,9\% e 81,4\% de seus municípios com nível de desenvolvimento moderado ou alto em termos do IFDM geral. No entanto o estado de Mato Grosso do Sul apresenta apenas quatro (4) municípios com nível de desenvolvimento alto, ou seja, o pior resultado em termos absolutos em relação aos outros estados da região Centro-Oeste.

Neste contexto, o presente artigo objetiva realizar uma análise descritiva baseada em dados secundários da evolução do Índice FIRJAN de desenvolvimento municipal, no período de 2005 a 2016, com base nas teorias da causação circular e acumulativa e do crescimento endógeno. Para tanto, utilizar-se-ão dois métodos de comparação: intrarregional e inter-regional. Em outros termos, o primeiro método visa confrontar o índice IFDM dos municípios do Mato Grosso do Sul à média do próprio Estado, e o segundo compara os municípios à média dos municípios brasileiros ${ }^{3}$.

Outros autores analisaram o nível de desenvolvimento dos municípios de Mato Grosso do Sul, entre eles, Duarte e Cavalcanti (2016), os quais avaliaram a relação entre a variação do PIB e a variação do Índice de Desenvolvimento Humano Municipal (IDHM) dos municípios da microrregião de Dourados, MS, entre 2000 e 2010; e Corrêa, Bidarra e Piffer (2019), que, por meio do Índice FIRJAN, analisaram a evolução do desenvolvimento socioeconômico dos municípios sul-mato-grossenses entre 2005 e 2013. Com referência a tais trabalhos, principalmente o segundo, a contribuição deste artigo se apresenta em duas diretrizes: análise com dados recentes e aperfeiçoamento metodológico. A primeira diz respeito a se analisar o período entre 2005 e 2016; e a segunda decorre do fato de se empregar uma metodologia com maior número de categorias para classificar o nível de desenvolvimento econômico dos municípios.

Este artigo está organizado da seguinte forma. Na próxima seção, apresentar-se-á o referencial teórico utilizado para alicerçar o presente artigo. Logo, será realizada nesta primeira seção uma breve discussão sobre o conceito de desenvolvimento econômico, das teorias da causação circular cumulativa e da teoria do desenvolvimento endógeno. Na seção seguinte, será apresentada a composição metodológica e as estimativas do índice FIRJAN de desenvolvimento municipal e suas principais diferenças em relação ao Índice de Desenvolvimento Humano Municipal. Na terceira seção, serão apresentados os resultados estatísticos, obtidos a partir dos dados secundários do índice FIRJAN, para o estado de Mato Grosso do Sul, no período entre 2005 e 2016, tratados e interpretados à luz do referencial teórico proposto. Nesta seção, apresentar-se-á como os pontos anteriores se relacionam para fundamentar os resultados da análise intrarregional e inter-regional dos municípios do estado de Mato Grosso do Sul. E, por fim, o artigo será concluído com a interpretação dos principais resultados obtidos no presente artigo.

\footnotetext{
${ }^{3}$ Nas análises intrarregional e inter-regional, o Índice FIRJAN de Desenvolvimento Municipal (IFDM) médio do estado e o do Brasil foram estimados, respectivamente, com base na média ponderada das populações existentes nos municípios sul-mato-grossenses e na média ponderada nos municípios brasileiros, em cada ano de referência. Dessa forma, cabe mencionar que as médias estadual e nacional divulgadas nos dados FIRJAN são diferentes das médias utilizadas neste artigo.
} 


\section{DISCUSSÃO E CONCEITUAÇÃO DE DESENVOLVIMENTO ECONÔMICO}

O conceito de desenvolvimento econômico na dimensão macroeconômica congrega, principalmente, como referência fundamental, as variáveis emprego e crescimento. Segundo Sen (1999; 2000), alguns autores da escola de pensamento econômica clássica utilizam o conceito de crescimento como equivalente ao conceito de desenvolvimento econômico, visto que, para os autores de tal vertente teórica, as benesses do crescimento econômico seriam distribuídas aos participantes do processo de produção segundo sua participação e, portanto, de maneira justa e não necessariamente equitativa.

Dessa forma, torna-se crucial definir e diferenciar crescimento e desenvolvimento econômico. O primeiro conceito faz referência ao processo de transformações estruturais da economia e da sociedade, o qual eleva os padrões de vida por meio da acumulação de capital e do avanço tecnológico nos processos de produção. Já o conceito de desenvolvimento econômico incorpora as dimensões sociais, políticas e ambientais. Em outras palavras, o desenvolvimento de um país engloba quatro objetivos políticos das sociedades modernas, a saber: a liberdade, o bem-estar, a justiça social e a proteção da natureza. Portanto, para se evoluir em termos de desenvolvimento econômico, é preciso fazer prevalecer a igualdade de oportunidades, liberdade e respeito ao meio ambiente (BRESSER-PEREIRA, 2007; RENZI; HENZ; RIPPEL, 2019).

A partir dessa perspectiva de desenvolvimento enquanto liberdade e igualdade de oportunidades, para Sen (1999; 2000), o desenvolvimento de uma nação pode ser avaliado do ponto de vista do processo de expansão das liberdades reais desfrutadas pelas pessoas em uma determinada nação. A partir dessa perspectiva, tal autor diferencia crescimento de desenvolvimento econômico ${ }^{4}$, na medida em que observa crescimento como um possível meio de ampliar as liberdades desfrutadas pelos integrantes da sociedade; no entanto as liberdades possuem uma gama de determinantes mais ampla, tais como: disposições econômico-sociais e direitos civis ${ }^{5}$. Isso significa que, para se evoluir em termos de desenvolvimento econômico, é preciso corrigir os fatores que influenciam na privação de liberdade, tais como insuficiência de oportunidades econômicas e destituição social sistemática, negligência dos serviços públicos e pobreza econômica6.

Portanto, nesta seção, realizou-se uma breve diferenciação entre os conceitos de crescimento econômico e desenvolvimento econômico. Adicionalmente, argumentou-se sobre a importância das dimensões sociais para se promover e acelerar a evolução das economias em desenvolvimento em termos da qualidade de vida dos países desenvolvidos.

\footnotetext{
${ }^{4}$ O crescimento econômico é avaliado como a evolução do Produto Interno Bruto per capita, e tal evolução pode ocorrer por meio da aceleração do processo de industrialização, do progresso técnico ou da modernização da sociedade. Esses fatores são fundamentais para ampliar a liberdade humana.

${ }^{5}$ As disposições econômico-sociais podem ser representadas pela gama de serviços públicos ofertadas (saúde, educação, lazer, cultura), e os direitos civis representam o grau de participação da população na discussão e tomada de decisão em assuntos públicos.

${ }^{6}$ A pobreza econômica é falta de liberdade para saciar a fome, obter remédios para doenças tratáveis, habitar em locais apropriados, ter acesso a saneamento básico e água tratada. Para mais detalhes sobre as limitações para se medir o desenvolvimento econômico de uma nação, veja o Informe sobre o Desarrollo Humano (PROGRAMA DAS NAÇÕES UNIDAS PARA O DESENVOLVIMENTO [PNUD], 2002).
} 


\subsection{Da teoria da causação circular à teoria do desenvolvimento endógeno das regiões}

A partir do grau de acesso aos bens públicos ofertados de forma a equalizar a igualdade de condições iniciais dos indivíduos presentes em uma determinada sociedade, é possível avaliar a oportunidade econômica e as condições sociais de inclusão dos indivíduos em termos de condições de concorrência equitativas entre os indivíduos. A métrica esperada é obter um sistema produtivo capaz de permitir uma distribuição da renda gerada condizente com a participação dos trabalhadores em tal sistema.

Com vistas a esse sistema produtivo ideal, Myrdal $(1965,1968)$ chama atenção para o princípio da causação circular e acumulativa, no qual argumenta que as condições sociais e econômicas vigentes em uma país subdesenvolvido explicam seus respectivos baixos níveis de desenvolvimento (ou, como definido por tal autor, como nível de pobreza ${ }^{7}$ ) e, por sua vez, dificultam a saída desses países de tais condições, ou pelo menos mantêm tais países numa taxa de desenvolvimento inferior aos países desenvolvidos. Tal autor ressalta ainda que o processo acumulativo pode atuar em ambas as direções, de forma que pode promover desigualdades crescentes entre países ou regiões. Dessa forma, como argumentam Raiher e Ferrera de Lima (2014), a ideia de causação circular acumulativa torna-se um elemento crucial para auxiliar no entendimento das desigualdades sociais e da dinâmica do desenvolvimento regional.

Outro ponto relevante ressaltado por Myrdal (1968) é a ideia de que o sistema econômicosocial não opera em um equilíbrio estável e não há uma tendência de autoestabilização de tal sistema. Logo, pode-se afirmar que existem forças e que elas fortalecem as desigualdades atuando em direção contrária à posição de equilíbrio estável. Tal argumento esclarece a ideia de causação circular, que é tida como um processo social com tendências a se tornar acumulativo e, na maioria das vezes, elevar, aceleradamente, sua velocidade. A partir daí advém uma das explicações de por que regiões mais pobres tendem a ampliar o hiato tecnológico em relação aos países mais desenvolvidos e, consequentemente, dificultar a trajetória em direção a níveis melhores de desenvolvimento econômico.

Com base em tal contexto, deve-se inferir que se faz necessária uma intervenção por meio de políticas públicas com vistas a romper o círculo vicioso da pobreza. Reitera-se que há possibilidade de o Estado ter um papel mais atuante junto aos investimentos em infraestrutura física e humana para alicerçar o desenvolvimento econômico. Para tanto, a política fiscal é uma ferramenta crucial para ajustar a demanda agregada, e a forma como tal política pode influenciar o nível de emprego e o salário é determinante para o crescimento de longo prazo de um país ou região (ARESTIS; SAWYER, 2003; 2005; RENZI; MEIRELLES, 2015).

Não se pode desconsiderar que uma economia regional difere da economia de uma nação por não existirem barreiras à migração, circulação de bens e serviços e circulação de capital (financeiro e humano) (RENZI et al., 2019) ${ }^{8}$. Em qualquer sociedade, existem fatores exógenos e endógenos capazes de fazerem avançar uma economia regional em direção à melhores níveis de desenvolvimento. O desenvolvimento endógeno decorre de as capacidades inerentes da sociedade local conduzirem o seu próprio desenvolvimento econômico, ficando tal

\footnotetext{
${ }^{7}$ Na seção posterior, serão discutidos os critérios para definir níveis de desenvolvimento econômico, porém o nível baixo de desenvolvimento econômico pode não representar o conceito de pobreza.

${ }^{8}$ Será considerado, neste artigo, a livre mobilidade de mercadorias entre estados brasileiros. Dessa forma, será desconsiderada a guerra fiscal e a cobrança do Imposto sobre Circulação de Mercadorias e Serviços (ICMS).
} 
desenvolvimento condicionado à mobilização dos fatores produtivos disponíveis na região em questão e ao seu potencial de dinamismo (AGHION et al., 1998; AMARAL FILHO, 2009; PIACENTI; EBERHARDT; FERRERA DE LIMA, 2016).

$\mathrm{Na}$ teoria do desenvolvimento endógeno, uma das suas contribuições mais importantes foi identificar quais fatores de produção são responsáveis por explicar uma considerável parcela dos resultados obtidos de uma determinada região, tais como: capital humano, capital social, conhecimento, pesquisa e desenvolvimento e informação (RENZI et al., 2019) ${ }^{9}$. Destarte, as regiões que possuírem tais fatores de produção, ou estiverem estrategicamente direcionadas a obtê-los no futuro, terão as mais adequadas condições de alcançar um desenvolvimento equilibrado e com tendências a acelerá-lo, a depender da interação dos fatores mencionados (AGHION et al., 1998; PIACENTI, EBERHARDT; FERRERA DE LIMA, 2016).

Na perspectiva regional, o crescimento econômico resulta da contínua evolução da eficiência em adicionar valor à produção e ampliar a parcela de renda a se absorver pela economia local, em decorrência da ampliação na capacidade de reter o excedente econômico produzido na economia local e/ou da atração de excedentes advindos de outras regiões. A evolução em tal processo tende a resultar na ampliação de produto, renda e emprego local. Nesse novo paradigma de desenvolvimento regional endógeno, o significado de desenvolvimento é alicerçado em sua estrutura pelos próprios atores locais; em outras palavras, parte das competências socioeconômicas peculiares à região ou ao local (AMARAL FILHO, 2009).

\section{PROCEDIMENTOS METODOLÓGICOS}

A partir da breve apresentação das teorias da causação circular acumulativa e do desenvolvimento endógeno, conclui-se que os aspectos mencionados anteriormente, ao serem identificados nas regiões em análise, serão utilizados como elementos intensificadores dos círculos virtuosos ou como ingredientes para interromper os círculos viciosos apontados por Myrdal $(1965,1968)$. Para tanto, foi construído o Quadro 1, que apresenta o método para classificar os municípios.

Quadro 1 - Classificação dos municípios quanto ao nível de desenvolvimento socioeconômico

\begin{tabular}{|c|l|l|}
\hline 1 & Ciclo Virtuoso & IFDM Emprego e Renda, Saúde e Educação > Média \\
\hline 2 & Tendendo ao Desenvolvimento Econômico & IFDM Saúde e Educação > Média \\
\hline 3 & $\begin{array}{l}\text { Tendendo ao Crescimento Econômico com } \\
\text { Educação }\end{array}$ & IFDM Emprego e Renda e Educação > Média \\
\hline 4 & $\begin{array}{l}\text { Tendendo ao Crescimento Econômico com } \\
\text { Saúde }\end{array}$ & IFDM Emprego e Renda e Saúde > Média \\
\hline 5 & $\begin{array}{l}\text { Tendendo à melhor formação de Capital } \\
\text { Humano }\end{array}$ & IFDM Educação > Média \\
\hline 6 & Tendendo a melhores condições de saúde & IFDM Saúde > Média \\
\hline 7 & Tendendo ao Crescimento Econômico & IFDM Emprego e Renda > Média \\
\hline 8 & Ciclo Vicioso & IFDM Emprego e Renda, Saúde e Educação < Média \\
\hline
\end{tabular}

Fonte: As categorias 3, 4, 5 e 6 foram construídas pelo autor, as outras foram elaboradas com base no Informe sobre Desarrollo Humano (PNUD, 2002), Raiher e Ferrera de Lima (2014) e Corrêa, Bidarra e Piffer (2019).

\footnotetext{
${ }^{9} \mathrm{O}$ capital social é denominado como a capacidade de os agentes locais serem os protagonistas e interagirem de modo cooperativo territorialmente, em busca do desenvolvimento da região.
} 
Destarte, neste artigo, será utilizado o Índice FIRJAN de Desenvolvimento Municipal (IFDM) como proxy para classificar a situação dos municípios do estado de Mato Grosso do Sul quanto à evolução do desenvolvimento econômico no período entre 2005 e 2016, e serão apresentadas as características do IFDM e as principais diferenças metodológicas em relação ao Índice de Desenvolvimento Humano Municipal (IDHM).

O IDHM é calculado por meio da média geométrica das três dimensões, a saber ${ }^{10}$ : padrão de vida representado pelo IDHM Renda, acesso ao conhecimento representado pelo IDHM Educação e, por fim, vida longa e saudável representado pelo IDHM Longevidade (Quadro 2) (ATLAS DO DESENVOLVIMENTO HUMANO DO BRASIL, 2013) ${ }^{11}$.

Quadro 2-Metodologia para cálculo do IDHM

\begin{tabular}{|c|c|c|}
\hline $\begin{array}{l}\text { Padrão de vida - } \\
\text { IDHM Renda }\end{array}$ & Acesso ao Conhecimento - IDHM Educação & $\begin{array}{l}\text { Vida Longa e Saudável - } \\
\text { IDHM Longevidade }\end{array}$ \\
\hline \multirow[b]{2}{*}{$\begin{array}{l}\text { Renda per capita do } \\
\text { município - incluindo } \\
\text { crianças e pessoas } \\
\text { sem registro de renda. }\end{array}$} & $\begin{array}{l}\text { A escolaridade da população adulta é medida pelo } \\
\text { percentual de pessoas de } 18 \text { anos ou mais de idade com } \\
\text { ensino fundamental completo - tem peso } 1 .\end{array}$ & \multirow{2}{*}{$\begin{array}{l}\text { Expectativa de vida ao } \\
\text { nascer - número médio } \\
\text { de anos que as pessoas } \\
\text { viveriam a partir do } \\
\text { nascimento, mantidos } \\
\text { os mesmos padrões de } \\
\text { mortalidade observados } \\
\text { no ano de referência. }\end{array}$} \\
\hline & $\begin{array}{l}\text { O fluxo escolar da população jovem é medido pela } \\
\text { média aritmética do percentual de crianças de } 5 \text { a } 6 \text { anos } \\
\text { frequentando a escola, do percentual de jovens de } 11 \text { a } 13 \\
\text { anos frequentando os anos finais do ensino fundamental, } \\
\text { do percentual de jovens de } 15 \text { a } 17 \text { anos com ensino } \\
\text { fundamental completo e do percentual de jovens de } 18 \text { a } \\
20 \text { anos com ensino médio completo - tem peso } 2 \text {. }\end{array}$ & \\
\hline
\end{tabular}

Fonte: Elaboração própria a partir da metodologia desenvolvida pela PNUD (2014).

No intuito de aperfeiçoar o instrumento de avaliação da evolução do desenvolvimento econômico dos municípios brasileiros, utilizando-se das mesmas dimensões do desenvolvimento econômico, o Índice FIRJAN é composto pela média simples dos resultados alcançados nas dimensões emprego e renda, educação e saúde (Quadro 3) (IFDM, 2014) ${ }^{12}$.

Quadro 3 - Metodologia para cálculo do Índice FIRJAN de desenvolvimento municipal

\begin{tabular}{|c|c|c|c|c|c|}
\hline Emprego e Renda & Pesos & Educação & Pesos & Saúde & Pesos \\
\hline $\begin{array}{c}\text { Crescimento real de emprego } \\
\text { formal }\end{array}$ & $10 \%$ & $\begin{array}{c}\text { Matrículas na Educação } \\
\text { Infantil }\end{array}$ & $20 \%$ & $\begin{array}{c}\text { Número de consultas pré- } \\
\text { natal }\end{array}$ & $25 \%$ \\
\hline $\begin{array}{c}\text { Crescimento real da absorção } \\
\text { de mão de obra local }\end{array}$ & $10 \%$ & $\begin{array}{c}\text { Abandono no ensino } \\
\text { fundamental (1-tx) }\end{array}$ & $15 \%$ & $\begin{array}{c}\text { Óbitos por causa mal } \\
\text { definida }\end{array}$ & $25 \%$ \\
\hline $\begin{array}{c}\text { Formalização do mercado de } \\
\text { trabalho }\end{array}$ & $30 \%$ & $\begin{array}{c}\text { Distorção Idade-Série no } \\
\text { Ensino Fundamental (1-dx) }\end{array}$ & $10 \%$ & $\begin{array}{c}\text { Óbitos infantis por causas } \\
\text { evitáveis }\end{array}$ & $25 \%$ \\
\hline $\begin{array}{c}\text { Crescimento real da geração } \\
\text { de renda formal }\end{array}$ & $10 \%$ & $\begin{array}{c}\text { Docentes com ensino } \\
\text { superior no ensino } \\
\text { fundamental }\end{array}$ & $15 \%$ & $\begin{array}{c}\text { Internação sensível à } \\
\text { atenção básica }\end{array}$ & $25 \%$ \\
\hline
\end{tabular}

\footnotetext{
${ }^{10} \mathrm{O}$ cálculo é obtido pela seguinte fórmula: $I D H M=\sqrt[3]{I D H M_{\text {Renda }} * I D H M_{\text {Educação }} * I D H M_{\text {Longevidade }}}$, Em que: $I D H M_{\text {Educação }}=\sqrt[3]{1 *(\text { Escolaridade população adulta }) *(2 * \text { Fluxo escolar da população jovem })}$

${ }^{11}$ Para mais detalhes sobre a metodologia de elaboração do IDHM, veja no sítio eletrônico do Atlas do Desenvolvimento Humano no Brasil (2013).

12 Para verificar cada uma das categorias que compõem as dimensões mencionadas na construção do IFDM, veja o apêndice metodológico no sítio eletrônico do IFDM (2014).
} 


\begin{tabular}{|c|c|c|c|c|c|}
\hline Emprego e Renda & Pesos & Educação & Pesos & Saúde & Pesos \\
\hline $\begin{array}{c}\text { Crescimento real dos salários } \\
\text { médios do emprego formal }\end{array}$ & $10 \%$ & $\begin{array}{c}\text { Média de horas-aula diárias } \\
\text { no ensino fundamental }\end{array}$ & $15 \%$ & $25 \%$ & \\
\hline Massa salarial & $15 \%$ & $\begin{array}{c}\text { Resultado do IDEB no ensino } \\
\text { fundamental }\end{array}$ & & & \\
\hline \multicolumn{7}{|l|}{ Desigualdade - Gini } & $15 \%$ & & Fonte: Ministério da Saúde \\
\hline
\end{tabular}

Fonte: Elaboração própria, com base na metodologia do Índice FIRJAN (2014).

A partir da comparação entre o Quadro 2 e o Quadro 3, pode-se observar que o Índice FIRJAN de desenvolvimento municipal apresenta uma metodologia de cálculo com maior poder de explicação das dimensões do desenvolvimento econômico em relação ao IDHM. Enquanto o IDHM apresenta apenas a evolução da renda per capita, o IFDM na dimensão econômica apresenta, além da variável crescimento real da renda, as variáveis que medem a evolução da distribuição da renda e da massa salarial, o que, por sua vez, permite verificar a evolução da participação da massa salarial em relação ao PIB da região em questão e a melhora nas condições de desigualdade em termos de renda dos municípios.

Outro importante componente é a análise da evolução do mercado de trabalho local, tanto em relação à taxa de crescimento real do emprego formal quanto em relação à capacidade de absorção da mão de obra local e da formalização do mercado de trabalho. Tais variáveis permitem observar como o município tem evoluído na geração de novos postos de trabalho e se as políticas de desenvolvimento têm contribuído para ampliar o grau de formalização do mercado de trabalho no município. Além disso, permitem avaliar a evolução do crescimento real da renda formal e dos salários médios, observando as alterações da massa salarial e da desigualdade entre as faixas de renda.

Na dimensão da educação, diferentemente do IDHM, o Índice IFDM incorpora variáveis que permitem avaliar a qualidade da educação ofertada nos municípios analisados. As variáveis elencadas no Quadro 3 avaliam a educação em termos quantitativos (matrícula e abandono) e qualitativos (distorção de série, docentes com ensino superior no ensino fundamental, média de horas-aula diárias no ensino fundamental e resultado do Índice de Desenvolvimento da Educação Básica [IDEB]).

Para avaliar a saúde dos municípios, o IDHM utiliza como variável de análise a longevidade. Já o IFDM faz uma análise mais a profundada das condições de nascimento e morte ao nascer, além de observar as mortes de recém-nascidos por causas evitáveis e internações sensíveis à atenção básica. A partir de tais elementos de avaliação, as informações colhidas nesta dimensão pelo IFDM permitem uma análise mais apurada das condições de saúde disponíveis à população local.

O IFDM apresenta resultados para cada município, os quais podem variar entre 0 e 1 , considerando que os municípios que atinjam índices mais próximos a 1 apresentam maiores níveis de desenvolvimento local. Em decorrência, inicialmente serão elencados cinco intervalos nos quais os municípios serão classificados. Os intervalos de classificação são apresentados no Quadro 4, quais sejam: 
Quadro 4-Metodologia para classificação do nível de desenvolvimento municipal

\begin{tabular}{|c|c|c|}
\hline Nível de desenvolvimento & Intervalo & Legenda \\
\hline Baixo & $0-0,4$ & \\
\hline Regular & $0,4-0,6$ & \\
\hline Moderado 1 & $0,6-0,7$ & \\
\hline Moderado 2 & $0,7-0,8$ & \\
\hline Alto & $0,8-1,0$ & \\
\hline
\end{tabular}

Fonte: Elaboração própria, com base na metodologia do Índice FIRJAN (2014).

A metodologia apresentada foi utilizada para avaliar os 79 municípios do estado de Mato Grosso do Sul, entre 2005 e $2016^{13}$, e foi realizada a divisão da classificação em nível de desenvolvimento moderado 1 e 2. Tal fato se justifica pelo estado de Mato Grosso do Sul possuir 82,3\% dos seus municípios nessa situação em 2016 e para esclarecer com maior eficácia a evolução dos municípios no período proposto.

\section{ANÁLISE DOS RESULTADOS}

Com base na metodologia descrita na seção anterior e utilizando-se dos dados dos municípios do estado de Mato Grosso do Sul, foi elaborada a Figura 1, na qual se permite averiguar a evolução dos municípios do presente estado, entre 2005 e 2016. Pode-se afirmar que, em 2016, 8,9\% (7) dos municípios sul-mato-grossenses foram classificados com nível de desenvolvimento regular, 82,3\% (65) apresentaram desenvolvimento moderado (1 e 2) e 8,9\% (7) apresentaram nível de desenvolvimento alto. Cabe destacar que não houve nenhum município classificado com baixo nível de desenvolvimento no Índice FIRJAN geral em 2005 e 2016.

Na Figura 2, verifica-se que houve uma evolução significativa dos municípios no período analisado. Isso porque se constatou que uma considerável parcela dos municípios sul-matogrossenses classificados no nível regular (40,5\% em 2005 para 8,9\% em 2016) evoluiu das suas respectivas condições para o nível moderado. Em 2005, os municípios classificados no nível moderado ( 1 e 2 ) representavam 59,5\% e evoluíram para 82,3\% em 2016 . Por fim, no início do período analisado, não havia nenhum município classificado no nível alto de desenvolvimento do IFDM geral, mas, já no final do período, representavam 8,9\%.

\footnotetext{
${ }^{13}$ O município Paraíso das Águas foi incluído na análise utilizando como referência para o cálculo os valores dos índices e a média dos seus vizinhos (Água Clara, Camapuã, Costa Rica e Chapadão do Sul), uma vez que não apresenta dados FIRJAN suficientes para análise do período proposto. Já o município de Figueirão não apresentou dados FIRJAN para 2005 e 2006; dessa forma, esses anos foram estimados com base na média dos anos posteriores; ou seja, 2006 corresponde a uma média de 2007 e 2008, e 2005 corresponde a uma média dos anos de 2006 e 2007.
} 
Figura 1 - Gráfico de classificação (\%) dos municípios sul-mato-grossenses quanto aos Índices FIRJAN em 2005 e 2016

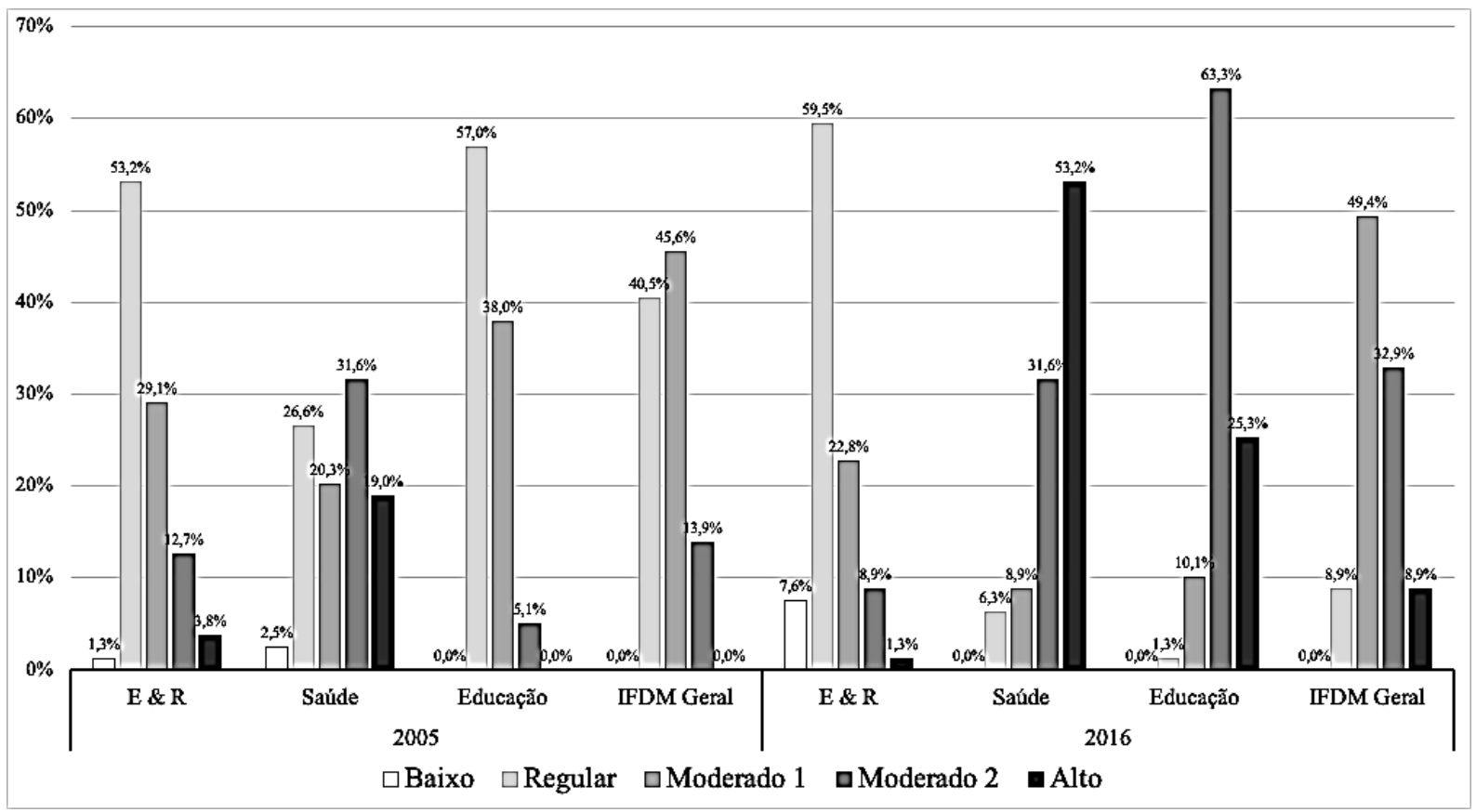

Fonte: Elaboração própria, a partir dos dados da FIRJAN.

De um modo geral, ao longo do período de análise, houve uma evolução de 0,72\% ao ano em termos de taxa média de crescimento geométrica do índice geral FIRJAN para os municípios de Mato Grosso do Sul, resultado superior à taxa média de crescimento geométrica nacional, que é de 0,47\% ao ano. Verificou-se que, enquanto o indicador FIRJAN de emprego e renda nacional evoluiu a uma taxa geométrica média anual de 1,24\% ao ano, houve uma involução desse indicador para os municípios sul-mato-grossenses (-1,09\% a.a.), o que, por sua vez, demonstra que a evolução no nível de desenvolvimento apontada na Figura 1 foi respaldada, principalmente, pela evolução nos índices de educação e saúde, os quais representaram, respectivamente, 2,3\% e 0,86\% ao ano, enquanto a média nacional foi de 0,52\% e 0,93\% ao ano. 
Figura 2 - Mapa dos municípios de Mato Grosso do Sul em relação ao índice geral FIRJAN 2005 a 2016

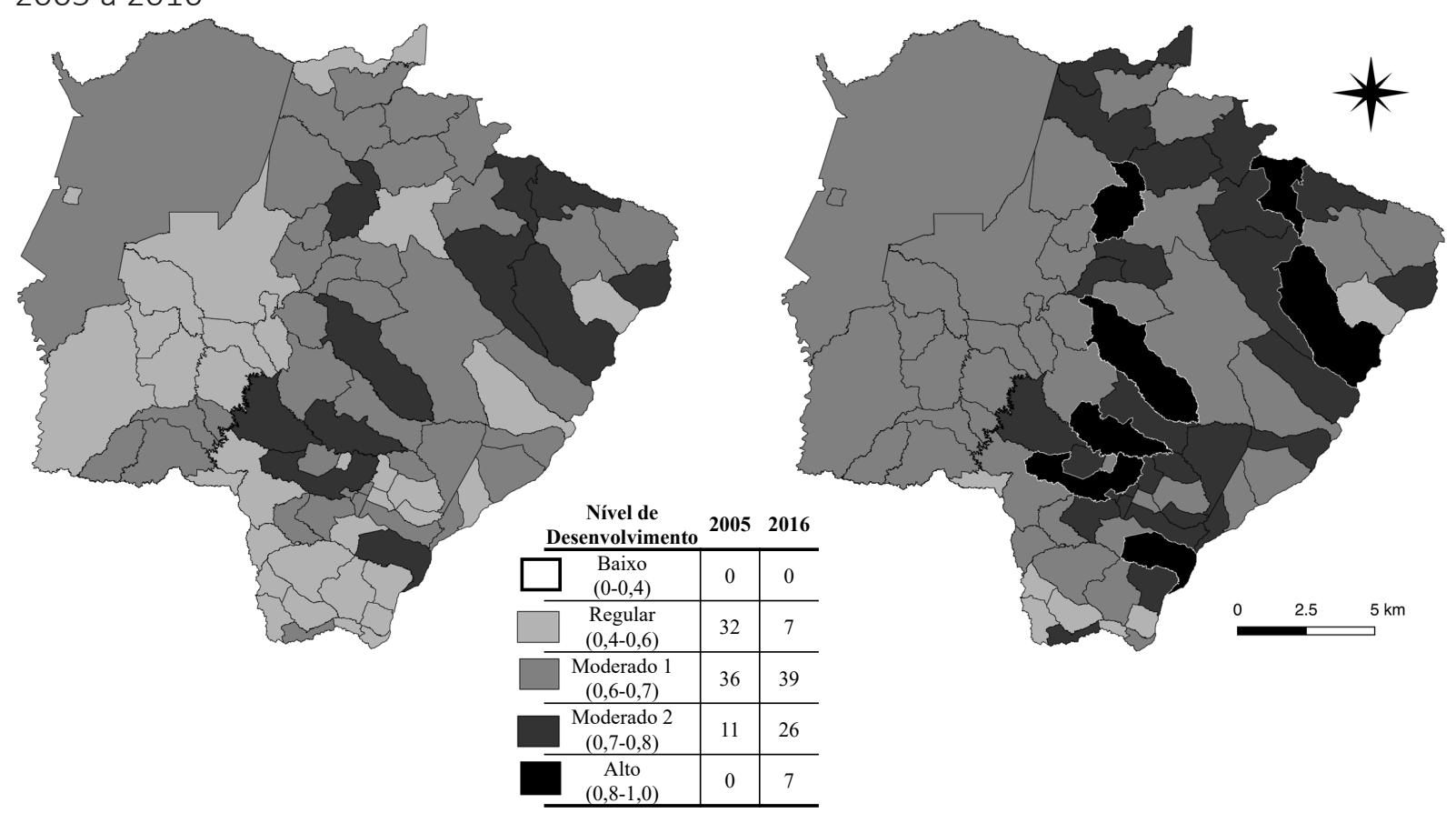

Fonte: Elaboração própria, a partir dos dados da FIRJAN (2014).

A Figura 2 apresenta a distribuição espacial dos municípios no estado sul-mato-grossense; nela, observa-se que a área mais desenvolvida em termos do índice geral FIRJAN se localiza na parte oeste do estado. Nessa mesma figura, pode-se observar os municípios com alto nível de desenvolvimento, em ordem decrescente e com as respectivas taxas geométricas médias de desenvolvimento econômico ao ano: 1으) São Gabriel do Oeste (0,66\% a. a.); 2ํ) Três Lagoas (0,91\% a. а.); 3ㅇ) Rio Brilhante (1,17\% a. a.); 4ㅇ) Campo Grande (0,27\% a. а.); 5ㅇ) Dourados (0,94\% a. а.); 6o) Naviraí (0,73\% a. a.); e 70) Chapadão do Sul (1,13\% a. a.), entre 2005 e 2016. Tais resultado foram puxados, principalmente, pelas dimensões saúde e educação. Para os sete municípios, as partes do índice compostas por essas duas dimensões apresentaram valores médios de 0,99\% e $2,07 \%$ ao ano, respectivamente.

Os sete piores resultados em termos da evolução do índice Geral FIRJAN foram encontrados para os municípios de Antônio João (73 e 2,55\% a. a.); Eldorado (74ㅇ e 2,09\% a. a.); Coronel Sapucaia (75 e 1,27\% a. a.); Japorã (76o e 1,84\% a. a.); Sete Quedas (77 e 1,55\% a. a.); Paranhos (78o e 2,68\% a. a.); e Tacuru (79 e 0,80\% a. a.). Apesar de esses municípios estarem classificados nas últimas posições, eles apresentaram resultados positivos em termos da evolução do índice geral FIRJAN. Isso porque esses resultados demonstram que esses municípios avançaram em termos do nível de desenvolvimento econômico medido pelo índice geral FIRJAN, no período entre 2005 e 2016, e foram puxados pelas dimensões saúde e educação, as quais representaram o valor médio, para os sete municípios, de 2,9\% e 2,79\% ao ano, respectivamente.

Portanto a identificação dos municípios que evoluíram em termos de desenvolvimento medidos pelo índice geral FIRJAN tem o intuito de sugerir um caminho inicial para observar a influência das dimensões emprego e renda, saúde e educação na determinação do nível de desenvolvimento econômico dos municípios do estado de Mato Grosso do Sul. 


\subsection{Análise inter-regional}

A partir da constatação feita na subseção anterior, em termos gerais, os municípios do estado de Mato Grosso do Sul estão se desenvolvendo a uma taxa média de crescimento geométrica superior à nacional, logo, faz-se necessária uma avaliação mais apurada para identificar e classificar de que forma tais municípios estão evoluindo comparativamente à média nacional. Para tanto, utilizou-se a metodologia de classificação descrita anteriormente no Quadro 1 e alicerçada na teoria da causação circular de Myrdal $(1965,1968)$ e na teoria do desenvolvimento endógeno (PIACENTI; EBERHARDT; FERRERA DE LIMA, 2016).

A partir das Figuras 3 e 4 (em seguida), com referência à média nacional, percebe-se que ocorreu um aumento do número de municípios (24 para 27) na situação de círculo vicioso da pobreza, com uma taxa de crescimento média geométrica de 1,0\% ao ano no período em análise. Assim, tais municípios estão tendendo a permanecer e agravar essa condição desfavorável e, por conseguinte, necessitam de uma análise mais apurada das políticas e dos investimentos realizados nas gestões municipais anteriores ao período da presente análise ${ }^{14}$.

Figura 3 - Gráfico da análise inter-regional e classificação dos municípios sul-mato-grossenses quanto ao nível de desenvolvimento entre 2005 e 2016

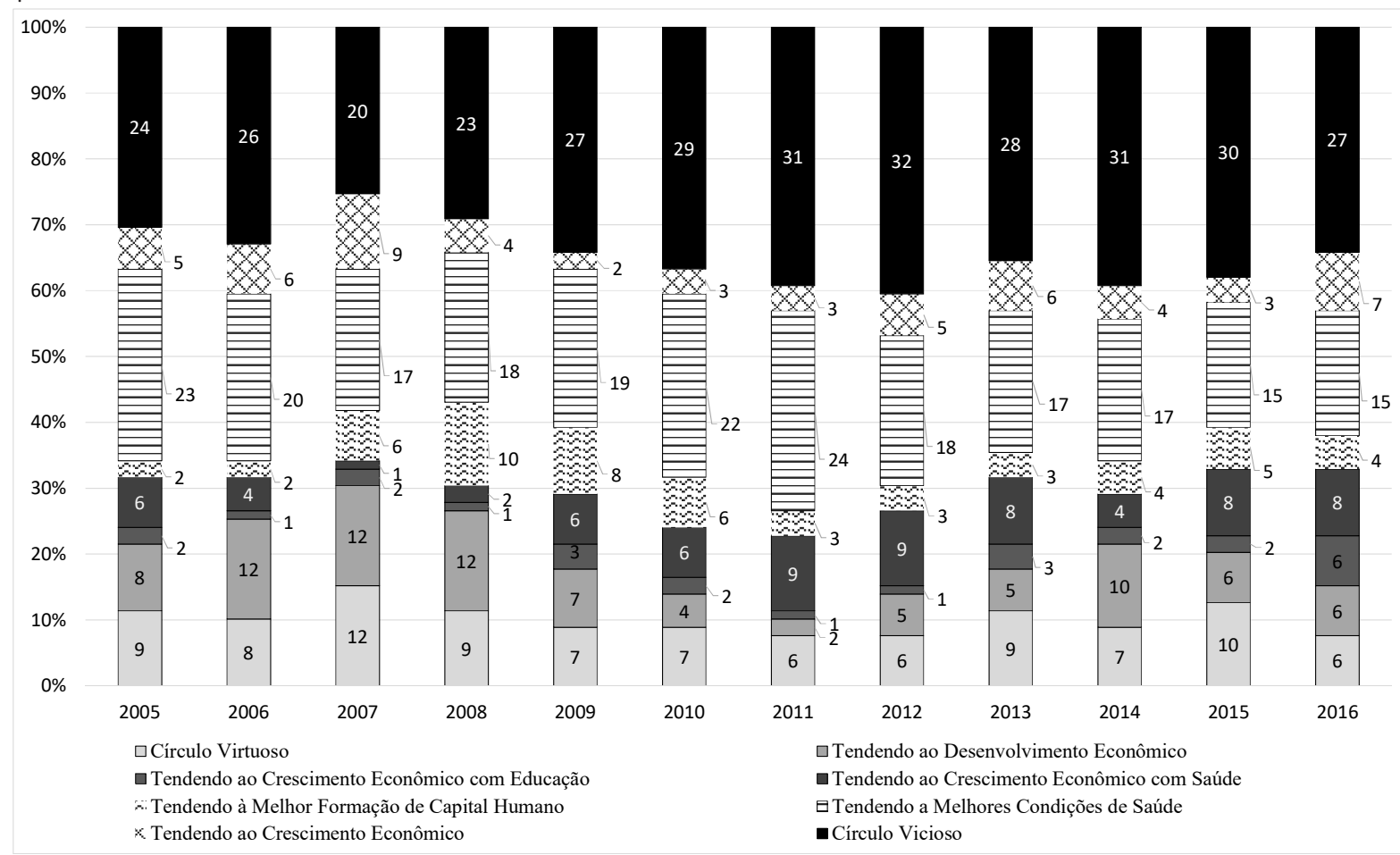

Fonte: Elaboração própria, a partir dos dados da FIRJAN (2014).

As outras categorias que apresentaram taxas geométricas positivas foram: aquela tendendo ao crescimento econômico com educação (8,0\% a. a.), a qual apresentou um aumento de dois para seis municípios; aquela tendendo ao crescimento econômico com saúde (2,3\% a. a.), que apresentou uma aumento de seis para oito municípios; e, por fim, a que apresentou evolução

\footnotetext{
${ }^{14}$ A análise das políticas e dos investimentos realizados pelos municípios do estado de Mato Grosso do Sul não é um dos objetivos do presente artigo. Pretende-se realizar tal agenda de pesquisa em outra oportunidade.
} 
positiva foi a que tendeu à melhor formação de capital humano (4,8\% a. a.), em que houve um aumento de dois para quatro municípios nessa situação.

Ainda com referência às Figuras 3 e 4, três categorias apresentaram involução: a categoria círculo virtuoso (- 3,2\% a. a.), em que houve um decréscimo de três municípios nessa situação, passando de nove para seis; a categoria tendendo ao desenvolvimento econômico (- 2,3\% a. a.), na qual o número de municípios reduziu de oito para seis; e, por fim, a categoria tendendo a melhores condições de saúde (- 3,6\% a. a.), em que houve uma redução de 23 para 15 municípios, entre 2005 e 2016.

Figura 4 - Gráfico da evolução inter-regional dos municípios de Mato Grosso do Sul, de 2005 a 2016

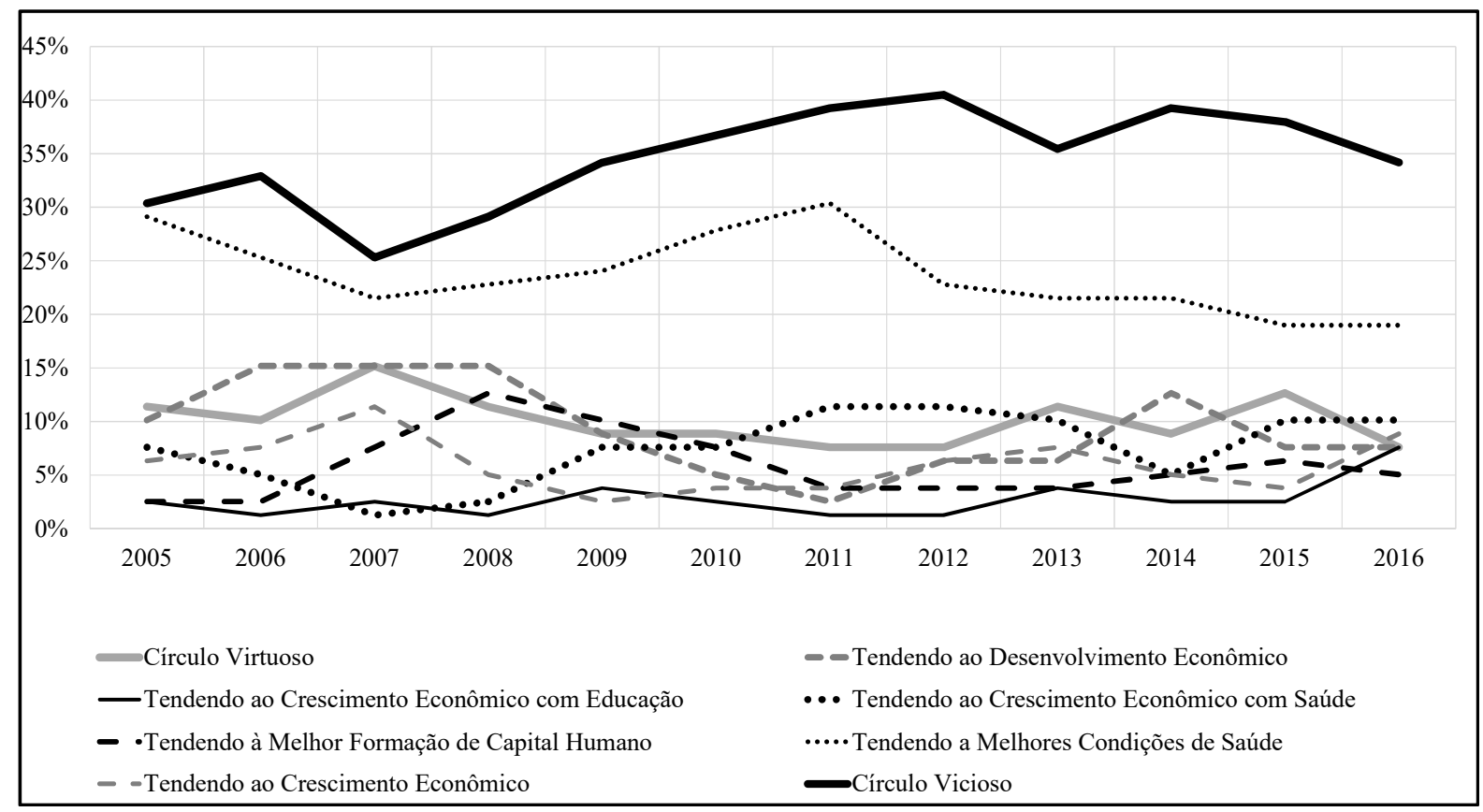

Fonte: Elaboração própria, a partir dos dados da FIRJAN (2014).

Os nove municípios que estavam na situação de círculo virtuoso em 2005 eram: Aparecida do Taboado, Campo Grande, Cassilândia, Dourados, Maracaju, Naviraí, Paranaíba, São Gabriel do Oeste e Três Lagoas. Em 2016, passaram a ser seis nessa categoria, são eles: Campo Grande, Naviraí, São Gabriel do Oeste e Três Lagoas, que permaneceram nesta situação em relação a 2005, e os outros dois municípios classificados, Chapadão do Sul e Rio Brilhante. Cabe salientar que os municípios de Aparecida do Taboado, Cassilândia, Dourados, Maracaju e Paranaíba perderam o status de municípios caracterizados como círculo virtuoso de desenvolvimento econômico em 2016.

Para respaldar os resultados encontrados, foi realizado o teste t de Student a partir de duas amostras independentes para se avaliar as médias dos municípios do estado de Mato Grosso do Sul em comparação à média do restante dos municípios brasileiros. Os resultados demonstraram que as médias dos anos 2005 e 2016 das variáveis do índice FIRJAN geral saúde e emprego e renda apresentaram o valor calculado da estatística do teste t superior ao valor tabelado, com probabilidade bilateral inferior a $5 \%(p<0,05)$, o que leva à rejeição da hipótese nula e permite concluir, ao nível de confiança de $95 \%$, que as médias populacionais são diferentes para essas variáveis mencionadas (FÁVERO; BELFIORE, 2017). 
Adicionalmente, esse conjunto de variáveis apresentou o teste de Levene com valores de significância inferiores a 5\% e, portanto, pode-se concluir que as variâncias não são homogêneas ao nível de confiança de 95\%, exceto a variável do índice emprego e renda para 2016, que apresentou variância homogênea (nível de significância observado de 0,278). Por fim, os índices de saúde para o ano 2016 e de educação para os anos de 2005 e 2016 apresentaram variâncias não homogêneas, e as suas médias populacionais são iguais (FÁVERO; BELFIORE, 2017).

Com referência às estatísticas apresentadas, a Figura 5 ilustra a localização dos municípios, espacialmente, e, diante dos resultados, pode-se afirmar que, em termos inter-regionais, os municípios sul-mato-grossenses apresentaram uma dinâmica de desenvolvimento econômico consideravelmente superior à do desenvolvimento nacional. Enquanto os municípios sul-matogrossenses evoluíram a uma taxa de 0,72\% ao ano, a média nacional foi de 0,47\% a. $a^{15}$.

Figura 5 - Perfil de desenvolvimento inter-regional dos municípios de Mato Grosso do Sul em 2005 e 2016

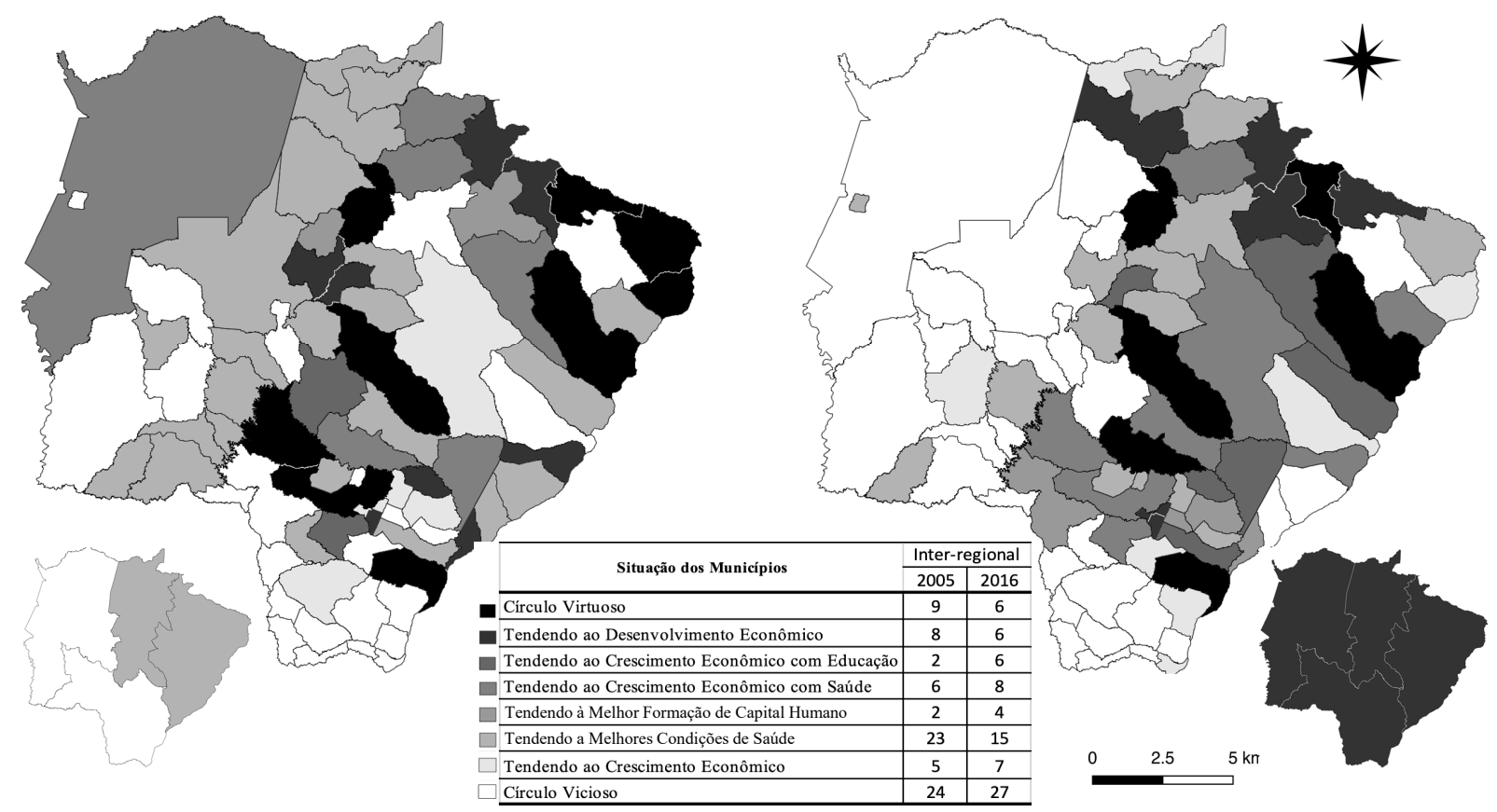

Fonte: Elaboração própria, a partir dos dados da FIRJAN (2014).

Apesar desse resultado, ao se observar a Figura 5, duas principais conclusões foram elaboradas. A primeira diz respeito ao fato de que a evolução mencionada transcorreu aumentando o número de municípios em situação de círculo vicioso e reduzindo os classificados como círculo virtuoso. Portanto, com referência a Myrdal (1965; 1968), isso induz à conclusão de que esses municípios estão encontrando dificuldades em superar o círculo vicioso da pobreza, tendendo a permanecer em tal situação e, ainda, afetando e espalhando tal condição para sua vizinhança. Adicionalmente, esse resultado também é corroborado por Corrêa, Bidarra e Piffer (2019), os quais observaram que os municípios na faixa de fronteira apresentaram elevados hiatos de desigualdade. A segunda principal conclusão indica que o processo de evolução dos

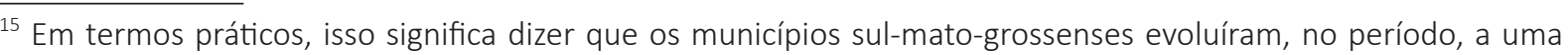
velocidade $53,2 \%$ superior à média nacional.
} 
municípios sul-mato-grossenses transcorreu, no período, concentrando o desenvolvimento econômico nos municípios localizados na porção Centro-Leste do estado.

Por fim, ainda sobre a Figura 5, empregando os valores médios dos municípios para avaliar o nível de desenvolvimento econômico das mesorregiões do estado, pode-se observar a evolução inter-regional das quatro mesorregiões do estado, isso porque as regiões Centro-Norte e Leste de Mato Grosso do Sul eram classificadas como tendendo a melhores condições de saúde, e as mesorregiões Pantanais Sul-Mato-grossenses e Sudoeste de Mato Grosso do Sul eram categorizadas por círculo vicioso em 2005. E tornaram-se, em 2016, mesorregiões classificadas como tendendo ao desenvolvimento econômico, com base em sua evolução em termos dos índices FIRJAN de saúde e educação.

A partir de tal constatação, pode-se intuir que as políticas de desenvolvimento regional postas em prática nos anos anteriores ao período em análise obtiveram algum sucesso nas dimensões saúde e educação, mas precisam ser revistas e remodeladas com referência à dimensão emprego e renda, isso porque, como argumentam Amaral Filho (2009) e Piacenti, Eberhardt e Ferrera de Lima (2016), o desenvolvimento endógeno depende da eficiência no emprego das potencialidades locais, à qual pode intensificar a aceleração da dinâmica de desenvolvimento dos municípios sul-mato-grossenses.

\subsection{Análise intrarregional}

Após a análise inter-regional, faz-se necessária uma análise intrarregional, a qual avalia a evolução dos municípios com referência à média do próprio estado e permite identificar quais são os municípios que se destacam comparativamente em Mato Grosso do Sul. Para tanto, será utilizada novamente a metodologia proposta no Quadro 1.

Figura 6 - Gráfico da análise intrarregional e classificação dos municípios sul-mato-grossenses quanto ao nível de desenvolvimento entre 2005 e 2016

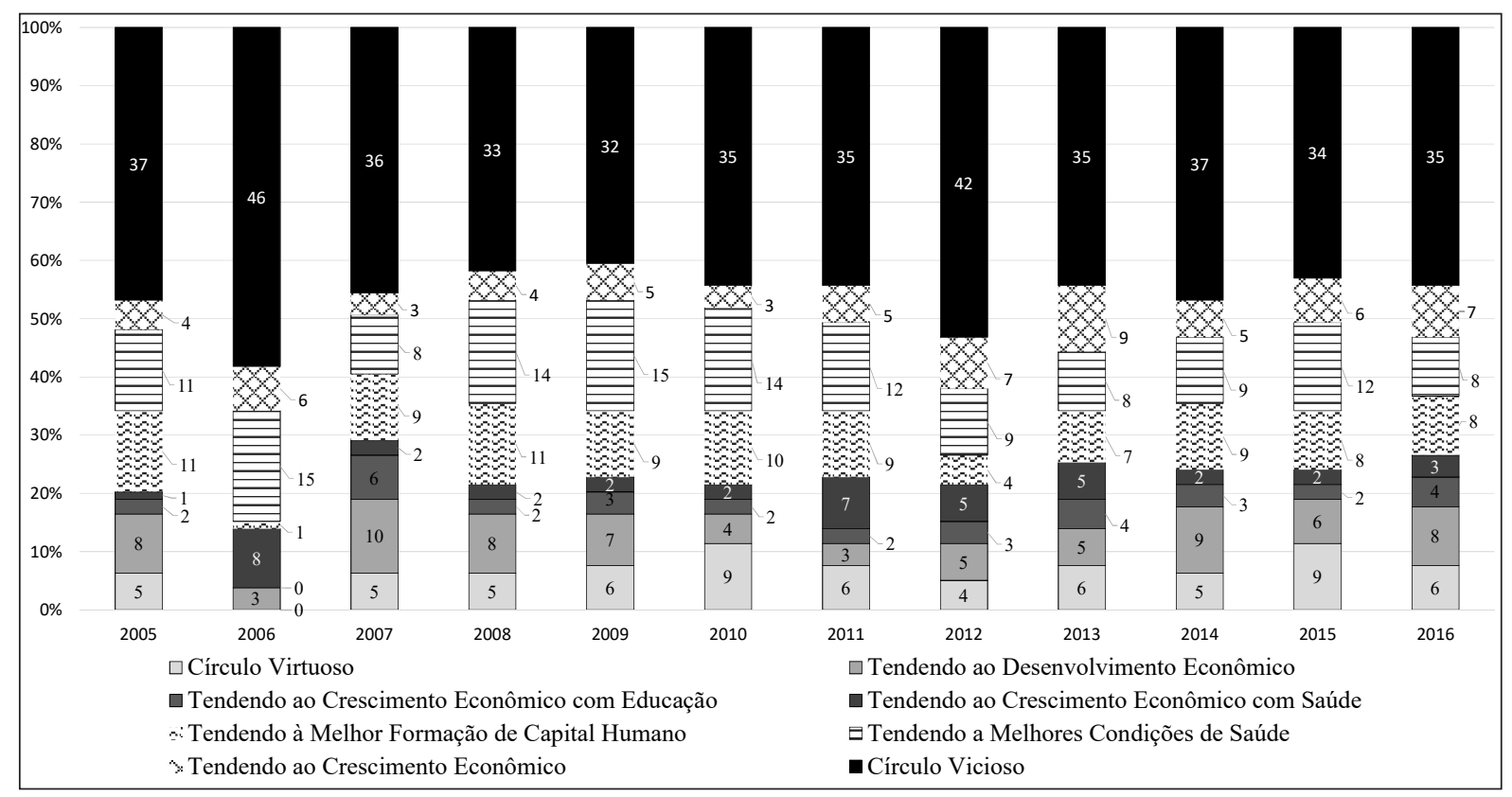

Fonte: Elaboração própria, a partir dos dados da FIRJAN (2014). 
Com base nas Figuras 6 e 7, nota-se que ocorreu a manutenção do número de municípios que se encontram na situação de tendendo ao desenvolvimento econômico (8). As categorias que apresentaram involução foram tendendo à melhor formação de capital humano $(-2,6 \%$ a. a.) e aquelas tendendo a melhores condições de saúde $(-2,6 \%$ a. a.) reduziram a participação do número de municípios de onze para oito; por fim, a categoria círculo vicioso (-0,5\% a. а.) apresentou uma ligeira queda, de 37 para 35 municípios, o que significa dizer que houve uma melhora nas condições em termos intrarregionais, com base nesta última categoria do desenvolvimento econômico.

Figura 7 - Gráfico da evolução intrarregional dos municípios de Mato Grosso do Sul de 2005 a 2016

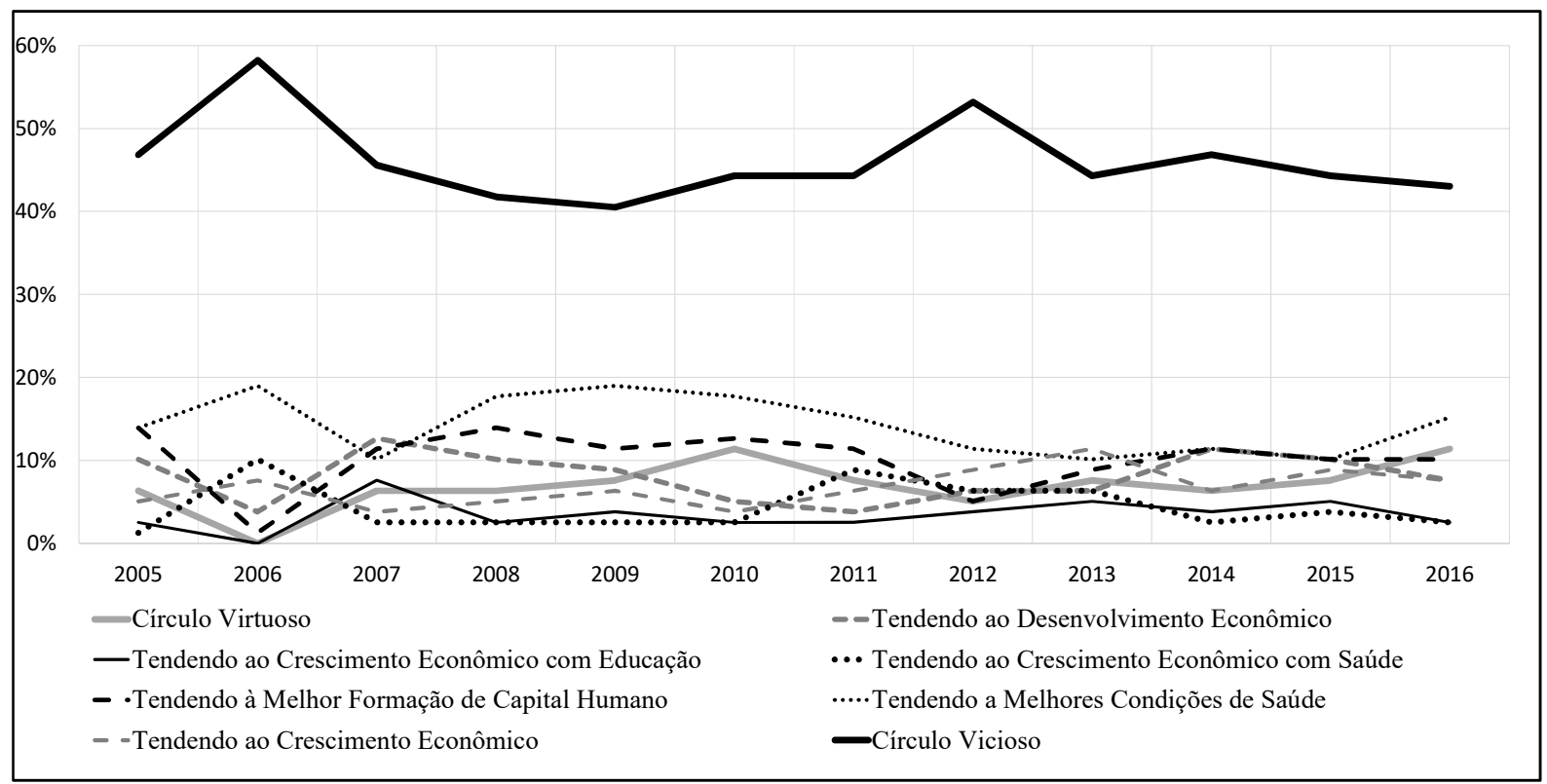

Fonte: Elaboração própria, a partir dos dados da FIRJAN (2014).

Os dados apontam a dimensão emprego e renda como principal causadora da situação de círculo vicioso, uma vez que $27(77,1 \%)$ dos municípios presentes nessa categoria apresentaram taxa média geométrica negativa (-1,02\%); nas outras dimensões, apresentaram taxas médias geométricas positivas na saúde (1,8\% a. a.), com 33 municípios (94,29\%), e na educação (2,51\% a. a), na totalidade dos municípios nessa situação. Esse fato induz à conclusão de que houve uma aceleração da concentração da riqueza e redistribuição da pobreza entre os municípios do estado.

Com relação aos 35 municípios classificados como círculo vicioso, foi calculada uma taxa média de crescimento geométrico de 1,18\% ao ano do índice FIRJAN geral para o período analisado. Essa taxa indica que os municípios classificados nessa categoria evoluíram a uma velocidade superior à taxa média de crescimento geométrico do estado $(0,72 \%$ a. a.) e à nacional $(0,42 \%$ a. a. $)$; no entanto isso não foi suficiente para retirá-los dessa condição desfavorável de desenvolvimento econômico, tendo em vista que a involução no índice de emprego e renda foi de $-1,02 \%$ ao ano. Outro ponto a destacar é o fato de que, na dimensão educação, os municípios do estado em círculo vicioso, em média, apresentaram evolução nas dimensões saúde e educação, com $1,67 \%$ e $2,48 \%$ ao ano. 
Complementarmente, observou-se que a explicação para melhora nas condições dos outros 44 municípios sul-mato-grossenses (não caracterizados como círculo vicioso) está relacionada, principalmente, à dimensão emprego e renda, não porque ela tenha apresentado progresso, mas porque apresentou uma menor taxa média de crescimento geométrico negativa (- 0,44\% a. a.) nesse período. Entre esses municípios, apenas 13 deles apresentaram essa taxa positiva ${ }^{16}$. Além disso, as dimensões saúde e educação evoluíram a 1,15\% e a 2,43\% ao ano, respectivamente, progresso esse ligeiramente inferior à média dos municípios caracterizados como círculo vicioso. Dessa forma, esses resultados apontam para o fato de que a evolução dos municípios sul-matogrossenses foi mais do que compensada pelas dimensões saúde e educação, principalmente pela dimensão educação, a qual cresceu a uma taxa geométrica média estadual da ordem de 2,30\% ao ano, superior à média nacional de 0,52\% ao ano.

Na Figura 8, pode-se observar a localização dos municípios classificados segundo as categorias descritas no Quadro 1. Nela, verifica-se que novamente os municípios localizados na porção Centro-Leste do estado compõem as melhores categorias do desenvolvimento econômico. E nas faixas de fronteira Oeste-Sul estão a maior parcela dos municípios categorizados nos piores níveis de desenvolvimento econômico, resultado similar ao encontrado por Corrêa, Bidarra e Piffer (2019).

Figura 8 - Perfil de desenvolvimento intrarregional dos municípios de Mato Grosso do Sul em 2005 e 2016

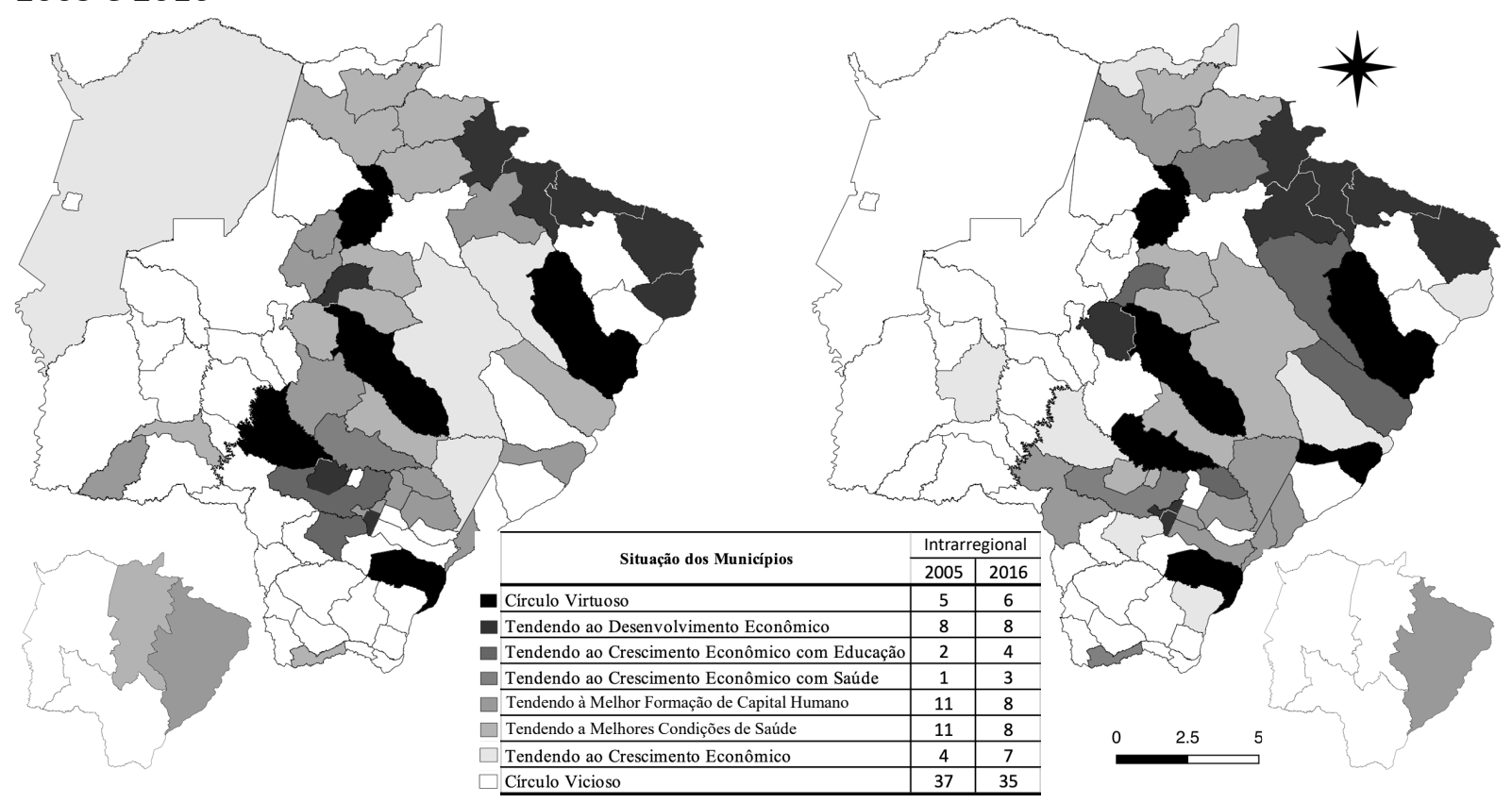

Fonte: Elaboração própria, a partir dos dados da FIRJAN (2014).

Ainda sobre a Figura 8, empregando os valores médios dos municípios para avaliar o nível de desenvolvimento econômico das mesorregiões do estado, pode-se observar uma involução

\footnotetext{
${ }^{16}$ Os municípios que apresentaram taxa de crescimento média geométrica positiva ao ano na dimensão emprego e renda foram: 1ํ) Selvíria (3,92\%); 2으) Santa Rita do Pardo (3,84\%); 3ㅇ) Itaquiraí (2,96\%); 4ㅇ) Sonora (2,82\%); 5ㅇ) Angélica (2,59\%); 6ㅇ) Rochedo (2,13\%); 7ㅇ) Bataguassu (0,98\%); 8ㅇ) Batayporã (0,62\%); 9ㅇ) Brasilândia (0,50\%); 10으) Bandeirantes (0,33\%); 11으) Chapadão do Sul (0,19\%); 12으) Jateí (0,06\%) e 13으) Pedro Gomes (0,01\%).
} 
intrarregional em termos mesorregionais do estado, isso porque as regiões Centro-Norte e Leste de Mato Grosso do Sul eram classificadas, respectivamente, como tendendo a melhores condições de saúde e como tendendo à melhor formação de capital humano, e as outras mesorregiões, Pantanais Sul-Mato-Grossenses e Sudoeste de Mato Grosso do Sul, eram categorizadas por círculo vicioso em 2005. A involução observada se verifica na mesorregião Centro Norte, que passou a ser classificada como círculo vicioso em 2016.

Portanto a análise intrarregional alicerça a afirmação de que ocorreu uma redistribuição da desigualdade entre as regiões presentes no estado e, similarmente à análise inter-regional, as dimensões educação e saúde alicerçaram ou sustentaram o nível de desenvolvimento econômico dos municípios ou regiões sul-mato-grossenses em detrimento da dimensão emprego e renda. Em decorrência, a partir das ideias de Myrdal $(1965,1968)$, as políticas de desenvolvimento regional imbuídas de dinamizar as atividades econômicas despontam como ações primordiais para romper a situação de círculo vicioso da pobreza e intensificar a dinâmica de desenvolvimento dos municípios sul-mato-grossenses.

\section{CONCLUSÃO}

O presente artigo realizou o objetivo proposto de fazer uma análise descritiva da evolução do Índice FIRJAN de desenvolvimento municipal, no período de 2005 a 2016, com base na teoria da causação circular cumulativa e na teoria do desenvolvimento endógeno.

Para concretizar tal objetivo, utilizaram-se dois métodos de comparação: intrarregional e inter-regional. Em termos inter-regionais, a evolução dos municípios sul-mato-grossenses transcorreu de forma menos dinâmica em comparação à dinâmica nacional, isso porque houve aumento no número de municípios qualificados como situação de círculo vicioso e a redução daqueles qualificados como círculo virtuoso. Em contraposição, na análise intrarregional, verificouse que ocorreu uma queda no número de municípios qualificados como círculo vicioso e o aumento daqueles classificados como círculo virtuoso. No entanto o processo de evolução dos municípios sul-mato-grossenses em termos mesorregionais aponta para uma redistribuição da riqueza em termos intrarregionais, mas com um progresso significativo na dimensão educação e saúde, superior à média nacional. Isso significa que as mesorregiões do estado progrediram, no período, de forma mais dinâmica em comparação à média nacional.

A partir desses resultados, pode-se inferir que 98,73\% dos municípios sul-mato-grossenses melhoraram sua condição em termos de desenvolvimento econômico no período analisado. Apenas o município de Corumbá $(-0,29 \%$ a. a.) apresentou taxa de crescimento média geométrica negativa no índice geral FIRJAN no período entre 2005 e 2016. Desse resultado, decorre o fato de que há uma tendência de os municípios sul-mato-grossenses reduzirem o hiato de desigualdade em relação aos municípios dos outros estados com maiores níveis de desenvolvimento econômico. Isso porque a taxa média de crescimento geométrica dos municípios sul-mato-grossenses $(0,72 \%$ a. a.) é consideravelmente superior à média nacional (0,47\% a. a.). Em termos práticos, os municípios sul-mato-grossenses evoluíram a uma velocidade 53,2\% superior em comparação à média nacional, entre 2005 e 2016. Nessa circunstância, com referência ao aspecto inter-regional, é provável que esses municípios estejam avançando na busca por superar os obstáculos para suplantar os gargalos existentes nas localidades, mas parte dos municípios ainda é considerada como círculo vicioso da pobreza e tendeu a permanecer em tal situação no período analisado. 
Portanto, com referência aos resultados observados neste artigo, a política fiscal pode ser um instrumento eficaz para incentivar o protagonismo local do empresariado urbano e rural e para refrear e, posteriormente, reverter o círculo vicioso da pobreza nos municípios identificados. Além disso, dado o alicerce identificado nos resultados representados pelas dimensões saúde e educação, a manutenção e/ou investimentos nelas demonstrou a influência positiva de tais dimensões para o nível de desenvolvimento econômico das municipalidades sul-mato-grossenses.

Por fim, uma importante agenda de pesquisa será a de identificar quais são os mecanismos de irradiação da pobreza entre vizinhos (municípios). Uma vez que já identificados os municípios nas situações de desenvolvimento citadas, uma proposta de pesquisa futura é avaliar as políticas públicas efetivadas nas últimas duas décadas pelas prefeituras desses municípios. O objetivo será buscar subsídios para explicar por que os municípios do estado sul-mato-grossense evoluem a uma dinâmica superior à média nacional, mas não superam a situação de círculo vicioso da pobreza.

\section{REFERÊNCIAS}

AGHION, P.; LJUNGQVIST, L.; HOWITT, P.; HOWITT, P. W.; BRANT-COLLETT, M.; GARCÍA-PEÑALOSA, C. Endogenous growth theory. London: MIT Press, 1998.

AMARAL FILHO, J. A endogeneização no desenvolvimento econômico regional e local. Planejamento e políticas públicas, Brasília, n. 23, p. 261-86, 2009. Disponível em: http://www.ipea.gov.br/ppp/index.php/ PPP/article/view/78. Acesso em: 22 abr. 2018.

ARESTIS, P.; SAWYER, M. Aggregate demand, conflict and capacity in the inflationary process. Cambridge Journal of Economics, Cambridge, v. 29. n. 6, p. 959-74, 2005. Disponível em: https://academic.oup.com/ cje/article-abstract/29/6/959/1685570. Acesso em: 12 mar. 2019.

ARESTIS, P.; SAWYER, M. Reinventing fiscal policy. Journal of Post Keynesian Economics, Annandale-on-Hudson, v. 26 n. 1, p. 3-26, 2003. Disponível em: https://www.econstor.eu/bitstream/10419/31523/1/503961485. pdf. Acesso em: 13 ago. 2019.

ATLAS DO DESENVOLVIMENTO HUMANO NO BRASIL. O índice de desenvolvimento humano municipal brasileiro. PNUD, [s.l.], 2013. Disponível em: http://www.atlasbrasil.org.br/consulta. Acesso em: 22 out. 2016.

BRESSER-PEREIRA, L. C. Macroeconomia da estagnação: crítica da ortodoxia convencional no Brasil pós1994. São Paulo: Editora 34, 2007.

CORRÊA, A. S.; BIDARRA, Z. S.; PIFFER, M. Desigualdades e desenvolvimento humano municipal no estado de Mato Grosso do Sul entre os anos de 2005 e 2013. Revista Brasileira de Gestão e Desenvolvimento Regional, Taubaté, v. 15, n. 2, p. 164-73, 2019. Disponível em https://www.rbgdr.com.br/revista/index. php/rbgdr/article/view/4458. Acesso em: 5 mar. 2020.

DUARTE, V. N.; CAVALCANTI, K. A. Produto Interno Bruto (PIB) versus Índice de Desenvolvimento Humano Municipal (IDHM) na microrregião de Dourados/MS. Desenvolvimento Regional em debate-DRd, Canoinhas, v. 6, n. 1, p. 120-35, 2016. Disponível em: https://dialnet.unirioja.es/servlet/articulo?codigo=5443876. Acesso em: 23 mar. 2020.

FÁVERO, L. P.; BELFIORE, P. Manual de análise de dados. Rio de Janeiro: Elsevier, 2017.

MYRDAL, G. O valor em teoria social. São Paulo: Editora USP, 1965. 
MYRDAL, G . Teoria econômica e regiões subdesenvolvidas. Rio de Janeiro: Editora Saga de São Paulo, 1968.

PIACENTI, C. A.; EBERHARDT, P. H. C.; FERRERA DE LIMA, J. (Org.). Economia e desenvolvimento regional. Foz do Iguaçu: Itaipu, 2016.

PROGRAMA DAS NAÇÕES UNIDAS PARA O DESENVOLVIMENTO [PNUD]. Informe sobre desarrollo humano: México, 2002. Ciudad de México: PNUD / Mundi-Prensa México, 2002 [Informe]. Disponível em: http:// hdr.undp.org/sites/default/files/mexico_2002_sp.pdf. Acesso em: 11 jun. 2019.

RAIHER, A. P.; FERRERA DE LIMA, J. Desenvolvimento humano municipal no Sul do Brasil: evolução recente e o círculo vicioso da pobreza. Acta Scientiarum. Human and Social Sciences, Maringá, v. 36, n. 2, p. 147-54, 2014. Disponível em: https://doi.org/10.4025/actascihumansoc.v36i2.24809. Acesso em: 24 ago. 2021.

RENZI, A.; DE PAULA JUNIOR, A.; FERREIRA, G. L. M.; PARRE, J. L. Capital humano: uma análise dos municípios paranaenses com econometria espacial. In: ENCONTRO DE ECONOMIA DA REGIÃO SUL, 12., 05 jul. 2019, Maringá. Anais [...]. Maringá: UEM; PCE, 2019. Disponível em: https://www.anpec.org.br/ sul/2019/submissao/files_l/i3-989606650b20250748c0c2a1e82831d4.pdf. Acesso em: 27 set. 2019.

RENZI, A.; HENZ, A. P.; RIPPEL, R. Desenvolvimento econômico: do crescimento à prosperidade. Revista Brasileira de Gestão e Desenvolvimento Regional, Taubaté, v. 15, n. 6, p. 65-77, 2019. Disponível em: https://www.rbgdr.net/revista/index.php/rbgdr/article/view/5185/843. Acesso em: 8 dez. 2019.

RENZI, A.; MEIRELLES, J. G. P. Um modelo kaleckiano com gasto público em educação. Economia e Sociedade, Campinas, v. 23, n. 2, p. 319-39, 2015. Disponível em: https://doi.org/10.1590/s010406182014000200002. Acesso em 24 ago. 2021.

SEN, A. K. Desenvolvimento como liberdade. São Paulo: Companhia das Letras, 2000.

SEN, A. K. Sobre ética e economia. São Paulo: Companhia das Letras, 1999.

\section{Sobre os autores:}

Adriano Renzi: Doutor em Desenvolvimento Regional e Agronegócios pela Universidade Estadual do Oeste do Paraná (UNIOESTE). Mestre em Desenvolvimento Econômico pela Universidade Federal do Paraná (UFPR). Graduado em Ciências Econômicas pela Universidade Estadual Paulista "Júlio de Mesquita Filho" (UNESP). Atualmente, é professor titular na Universidade Federal da Grande Dourados (UFGD). E-mail: adrianorenzi@ufgd.edu.br, Orcid: http://orcid.org/0000-0002-4336-5304

Jandir Ferrera de Lima: Doutor em Desenvolvimento Regional pela Universidade do Québec (UQAC), Canadá. Mestre em Economia pela Universidade Federal da Bahia (UFBA). Bacharel em Ciências Econômicas pela Universidade de Cruz Alta (UNICRUZ). Professor do mestrado em Economia e do mestrado e doutorado em Desenvolvimento Regional e Agronegócio na Universidade Estadual do Oeste do Paraná (UNIOESTE). Bolsista de Produtividade em Pesquisa do Conselho Nacional de Desenvolvimento Científico e Tecnológico (CNPq). Pesquisador do Núcleo de Desenvolvimento Regional na UNIOESTE. E-mail: jandirbr@yahoo.ca, Orcid: http://orcid.org/0000-0002-0359-0670

Carlos Alberto Piacenti: Doutor Honoris Causa em Economia pela Universidad Nihon Gakko, Paraguai. Doutor em Economia Aplicada e mestre em Economia Rural pela Universidade Federal 
de Viçosa (UFV). Graduado em Ciências Econômicas pela Faculdade de Ciências Econômicas do Sul de Minas (FACESM). Professor associado na Universidade Estadual do Oeste do Paraná (UNIOESTE), no curso de graduação em Economia e no programa de pós-graduação em Desenvolvimento Regional e Agronegócio. Perito no Conselho Estadual de Educação. Professor visitante da Escuela Venezolana de Planificación, da Venezuela. E-mail: piacenti8@gmail.com, Orcid: http://orcid.org/0000-0001-6874-7379 